\title{
Gradient Distribution Patterns of Rhizosphere Bacteria Associated with the Coastal Reclamation
}

\author{
Yu Zhang ${ }^{1} \cdot$ Baoshan Cui $^{1} \cdot$ Tian Xie $^{1} \cdot$ Qing Wang ${ }^{1} \cdot$ Jiaguo Yan $^{1}$
}

Received: 5 April 2015 / Accepted: 5 November 2015 /Published online: 2 February 2016

(C) The Author(s) 2016. This article is published with open access at Springerlink.com

\begin{abstract}
The main aim of the study was to assess the gradient distribution and composition diversity of microbial taxa using a spatial scale with physicochemical heterogeneity between reclamation area and non-reclamation area. The grid method was utilized to set the sample belt and sample square. The Illumina MiSeq platform was used to study the gradient distribution of rhizosphere bacteria in reclamation and nonreclamation areas. Operational taxonomic units were used to measure bacterial relative abundance. The analysis results showed salt concentration can effect on differences in bacterial relative abundance and composition diversity due to a variable in the rhizosphere soil. Bacterial relative abundance in reclamation area was significantly lower than that in nonreclamation area. The bacterial community composition showed a statistically significant to spatial variability. Some bacterial phyla exit in the whole study area, out of accordance with salinity control. It means that the composition of bacterial community was varied for the environment disturbance, but it was not unique correlated to environment factor. Anaerolinea genus has significantly positive correlation with salinity. It indicated that Anaerolinea genus can provide an indicator to response the environment change.
\end{abstract}

Keywords Gradient distribution - Rhizosphere bacteria . Coastal reclamation $\cdot$ Illumina MiSeq

Baoshan Cui

cuibs@bnu.edu.cn

1 School of Environment, Beijing Normal University, State Key Joint Laboratory of Environmental Simulation and Pollution Control, No. 19 Xinjiekouwai Street, Beijing 100875, China

\begin{abstract}
Abbreviations
OTUs Operational taxonomic units

PD_whole_tree Phylogenetic diversity whole tree
\end{abstract}

\section{Introduction}

The demand for land increases with the development of socioeconomic activities and population growth. Reclamation has become an effective method to alleviate the shortage of land supply, expand social survival, and develop spaces. Many countries have adapted reclamation projects to provide land resources demanded by the population. Reclamation projects are well developed in countries such as Japan, Netherlands, and Korea (Yu and Zhang 2011). Reclamation has tremendous social and economic benefits, but may irreversibly impact the ecological environment (De et al. 2002; Marimuthu et al. 2005; Shen and Ehrenfeld 2009). Reclamation changes the natural ecological patterns and causes strong perturbation to the ecological system by changing various environmental factors (Fellet et al. 2011; Park et al. 2009).

The rhizosphere is an active interface for interchanging soil material and plant nutrition (Stottmeister et al. 2003). Rhizosphere microorganism has an important function in soil formation and development, organic matter transformation, ecosystem balance, soil environment cleaning or bioremediation (Toal et al. 2000). Moreover, rhizosphere bacteria may promote plant growth by increased nutrient uptake that are difficult to be absorbed and used by plants into absorbable and usable forms (Dobbelaere et al. 2003). Rhizosphere bacteria have unique function in cellulose degradation, nitrogen fixation, and decomposition course of some special compounds (Waldrop et al. 2012; López-Fuentes et al. 2012). The diversity of rhizosphere microorganism is inseparable from ecosystem structure and functions. Changes in 
rhizosphere microorganism species and quantity may reflect the change process of soil property, and may also be significant indicator for evaluating soil change from natural or anthropogenic disturbances (Prosser 2002). Much research here in China and abroad show that the community composition of microorganisms has some difference in various ecosystems (Lin et al. 2010; Chen et al. 2012; Dunbar et al. 2012; Knelman et al. 2012). Wetland ecosystem has the feature of water and land, and thus, the ecosystem with the richest biological diversity, highest productivity, and biggest ecosystem service values on earth (Moore and Hunt 2012). However, most studies in this field have focused on terrestrial ecosystems and aquatic ecosystems (Wang et al. 2000; Venosa and Zhu 2003). Studies on rhizosphere microorganism have been carried out late in wetlands ecosystem. These studies have been conducted to explore microbial resources available for bioremediation of degraded wetlands and provide necessary theoretical basis for restoring degraded wetlands. Recent studies have emphasized on the analysis of rhizosphere soil microbial community in saline, alkali soil, or petroleum pollution (Sarkar et al. 2012; Martin et al. 2014). Wetland ecosystem is a special ecological system and it is located at interactive border zone between waters and terrestrial systems (Douterelo et al. 2010). In such complex and special environment that involves the interaction of ocean and land and changed materials in gradient, rhizosphere microorganism has a significant function in maintaining the stability of the wetland ecosystem, mineral elements cycle, degradation of pollutants (Hartmana et al. 2008).

With comprehensive studies on rhizosphere microenvironment constantly enrich and development, studies on the disturbance of reclamation activities on rhizosphere microenvironment and self-repairing capability of rhizosphere bacteria are necessary for advancing microbial remediation in reclamation area of coastal wetland. Therefore, clarifying the difference in rhizosphere bacterial community between the reclamation area and the non-reclamation area and obtaining comprehensive understanding of rhizosphere bacterial community functional and structural changes associated with the coastal reclamation would contribute to resolve the long-term problems at the coastal zone.

\section{Materials and Methods}

\section{Study Area}

The Yellow River Delta is between $36^{\circ} 55^{\prime}-38^{\circ} 10^{\prime} \mathrm{N}$ and $118^{\circ} 07^{\prime}-119^{\circ} 10^{\prime} \mathrm{E}$ (Fig. 1). The Yellow River Delta, located in the north of Shandong Province, has been characterized as the largest and youngest wetlands in the warm temperate zone of China (Xu et al. 2004). The main types of reclamation in this area are port construction, aquaculture, salt pan, and sea farming (Cui et al. 2009). Port construction is a common reclamation process; sea embankment is basic project of port construction. Construction of sea embankment hinders normal matter and energy exchange between tidal wetlands and seawater. Thus, reclamation areas of our study are between the sea and the sea embankment.

Reclamation and non-reclamation areas are located in the erosion area of the Yellow River Delta, and these two areas are characterized by a temperate, semi-humid continental monsoon climate, with a mean annual precipitation of $590 \mathrm{~mm}$ and mean of 210 frost free days. The average maximum and minimum temperatures are $26^{\circ} \mathrm{C}$ in July and $-4{ }^{\circ} \mathrm{C}$ in January, respectively. Non-reclamation area is located in the north of reclamation area. Reclamation area is between $38^{\circ} 00^{\prime} 57^{\prime \prime}-$ $37^{\circ} 57^{\prime} 22^{\prime \prime} \mathrm{N}$ and $118^{\circ} 58^{\prime} 45^{\prime \prime}-119^{\circ} 00^{\prime} 39^{\prime \prime} \mathrm{E}$, and Nonreclamation area is between $38^{\circ} 03^{\prime} 20^{\prime \prime}-38^{\circ} 01^{\prime} 49^{\prime \prime} \mathrm{N}$ and $118^{\circ} 57^{\prime} 09^{\prime \prime}-118^{\circ} 58^{\prime} 28^{\prime \prime}$ E. The embankment was built on June 2013 in reclamation area, and the effect of embankment was prevented from the erosion of the tides.

\section{Research Methods}

\section{Sample Collection and Treatment}

Samples were collected on August 2013 based on the presence or absence of sea embankment in the reclamation and nonreclamation areas of coastal wetlands at the Yellow River Delta. Five sample belts were set the direction from the sea to the land along a transect perpendicular to the coastline, with an interval of $500 \mathrm{~m}$. Twelve sample squares of $50 \mathrm{~cm} \times 50 \mathrm{~cm}$ were set on each sample belt with an interval of two sampling squares of $200 \mathrm{~m}$. Each sampling area had a total of 60 sample squares, 120 sample squares in all (Fig. 1).

Soil type of the two study areas were sandy and clay soil, and the major plant was halophyte such as Spartina alterniflora. All the samples in the article were collected from rhizosphere soils of Spartina alterniflora. Rhizosphere soils were collected by shaking the plant roots and got the dropped rhizosphere soils (Veneklaas et al. 2003). The rhizosphere soil samples in an aseptic bag were placed in an ice box and brought back to the lab for treatment. A part of the fresh samples were used to determine the microbial indicators in the rhizosphere soil; the others were used to determine the physiochemical factors in the rhizosphere soil after freezing, drying, dispersing, milling, and sieving.

\section{Physiochemical Factors in Soils and Test Methods}

Fresh rhizosphere soil sample (100 g) was placed in an oven for $24 \mathrm{~h}$ to dry at $105{ }^{\circ} \mathrm{C}$ to determine soil moisture. Four grams of this soil sample was passed through a 100 mesh screen, placed in a centrifuge tube, added with $20 \mathrm{~mL}$ of deionized water, and allowed to set after oscillation for 


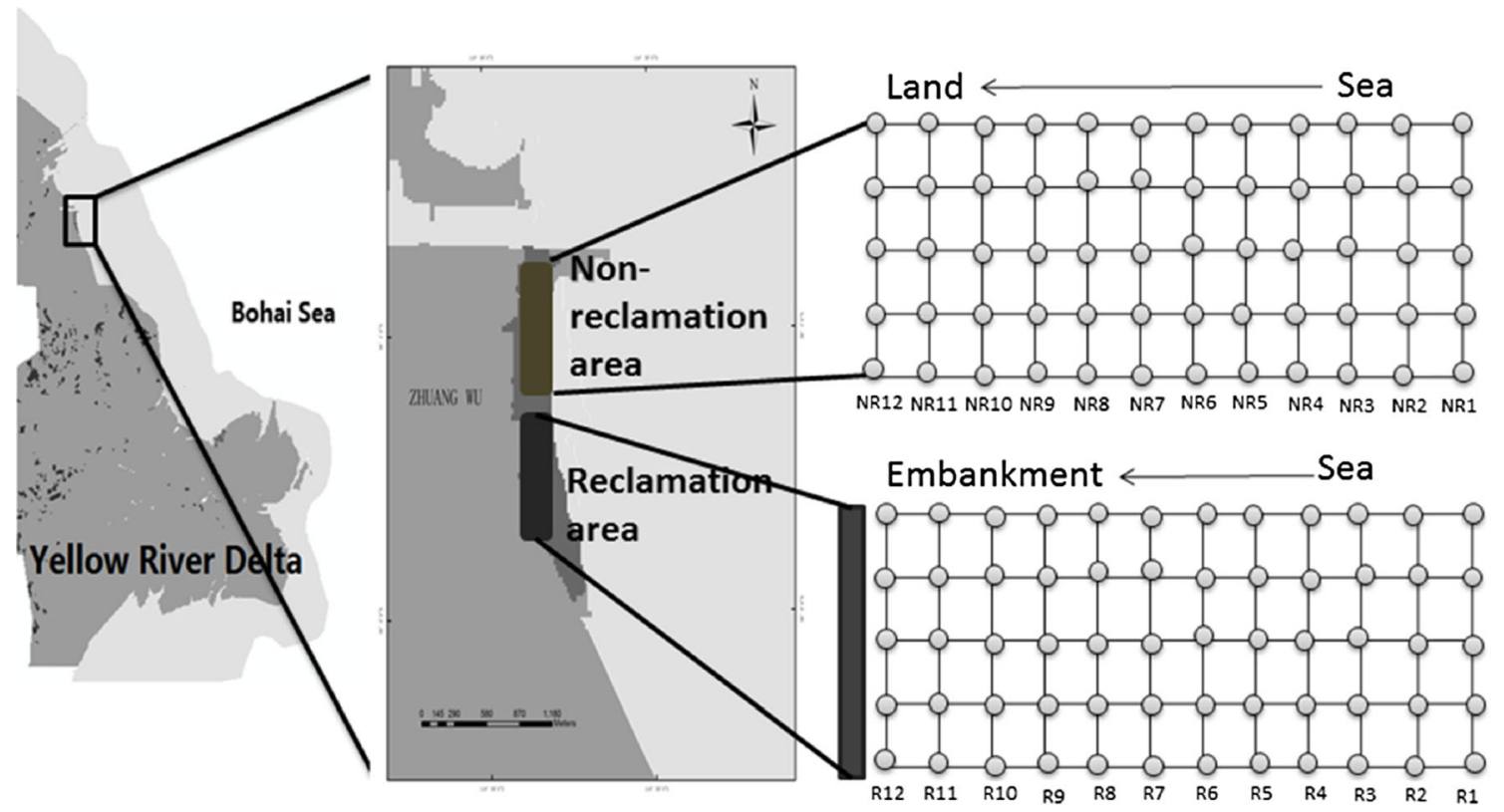

Fig. 1 Study area with the location of sample in the coast wetland

$30 \mathrm{~min}$. Conductivity meter was used to determine the soil salinity. Through a 100 mesh screen, the sediment sample was analyzed for total nitrogen (TN), total phosphorus (TP), and organic matter $(\mathrm{OM})$ content. $\mathrm{TN}$ in soils was determined by an elemental analyzer (Elementar, Germany); the soil was lixiviated in the acid mixture of $\mathrm{HClO}_{4}-\mathrm{HNO}_{3}-\mathrm{HF}$ $\left(\mathrm{HClO}_{4}: \mathrm{HNO}_{3}: \mathrm{HF}=2: 1: 1\right)$ to determine TP by inductively coupled plasma-atomic emission spectrometry; OM was determined by adapting the classic potassium dichromate method (Zhang et al. 2012; Jiang et al. 2008). Soil organic matter was calculated using the following the formula: organic matter $(\%)=$ organic carbon $(\%) \times 1.724$.

\section{Illumina Library Construction and Sequencing}

After using MO BIO Power soil DNA isolation kit, the rhizosphere soil DNA samples were purified by phenol, chloroform and isopentanol. The purified DNA samples were subjected to generate barcoded PCR products. Briefly, the V3 region of the bacteria 16S rRNA gene was amplified in triplicates for each sample with 338f518r primers containing a unique 12 bp barcode using Ex Taq Polymerase (Takara). The amplicons were purified by electrophoresis using $2 \%$ agarose gel and QIAquick Gel Extraction Kit (Qiagen). The final sequencing library was prepared by mixing equal amounts of purified PCR products, and then for end reparation and by addition of poly (A). Thereafter, the amplicons were connected with sequencing adapters. Following agarose gel electrophoresis, suitable fragments were selected as templates for PCR amplification. Finally, the library was sequenced by the Illumina MiSeq.

\section{Sequencing Data Regression Cluster Analysis}

The reads with a library size of $300 \mathrm{bp}$ were from Miseq sequencing machines and essential to data statistic. The quality of the reads was checked with FastQC, and the rawdata was assembled with Flash (Magoc and Salzberg 2011). The final results assembled were conducted by regression of sample on the basis of barcode sequence. OTU sequences were got after the clustering by clustering based on a $97 \%$ sequence similarity. And at last, program automatically chose the optimality OTU sequence from many of OTU sequences.

\section{Statistical Analysis}

Along the gradient direction, OTUs of rarefaction curves and bacterial community analysis were obtained by calculated the average of five sampling sites in the same distance from the sea to the land. To compare the significant difference of OTUs between reclamation area and non-reclamation area, correlation analysis was used by SPSS 13.0. Duncan's multiple range test analysis was conducted to compare the significant difference among the different sites of studied sample belts.

In order to compare the differences in the community composition correlated to the salinity of each site with others, a relative abundance matrix values have been calculated dividing the number of reads assigned to each phylum by the total number of reads present in each sequence file. The matrix was used to generate a heatmap plot, following the rhizosphere soil degree of salinity. Furthermore, a Canonical Correlation Analysis (CCA) was run with soil salinity, TN, TP and OM. Rhizosphere soil properties and abundance of microbial phyla were combined as variables in a principal component analysis 
(PCA), based on Spearman's rank correlation matrix. Origin pro 8, Prism5 and Mev 4.9.0 were employed to construct graphic data.

\section{Results}

\section{Distributions of Bacterial Relative Abundance and Physicochemical Factors}

$\mathrm{TN}$ of rhizosphere soil was observed to change between with 0.43 to $0.72 \%$ in non-reclamation area, and in reclamation area to change between with 0.42 to $0.82 \%$. Although TN content is uneven in the different locations of reclamation area, $\mathrm{TN}$ content has no significant difference in reclamation area and non-reclamation area. The results imply that reclamation has little influence on TN content. OM content (2.46$6.30 \%$ ) in non-reclamation area showed comparatively higher content than that (2.23-5.09\%) in reclamation area. OM and $\mathrm{TN}$ content increased gradually from the sea to the land in non-reclamation area. In reclamation area, the accumulation of TN and OM were increased near to the embankment. TP $(0.035-0.046 \%)$ oft rhizosphere soil in non-reclamation area was lower than that in reclamation area $(0.049 \%-0.073$ (Table 1). Rhizosphere soil salinity decreased gradually slowly between 2.55 and $1.55 \mathrm{~g} / \mathrm{L}$ from the sea to the land in nonreclamation area, and salinity varied significantly near to the embankment. The Kruskal-Wallis test showed significant differences in soil salinity in the reclamation and nonreclamation areas.

In total, 1286936 quality reads were generated with an average of $16,347 \pm 5737$ reads per sample after quality control used the QIIME pipeline (Caporaso et al. 2011). The overall number of OTUs detected by the rhizosphere bacterial reached 210,830 based on $\geq 97 \%$ sequence identity between reads.
The number of OTUs reached up to 33,150 in the $1800 \mathrm{~m}$ seaward from the land in non-reclamation area, and the number of OTUs reached up to 18,020 in the $2000 \mathrm{~m}$ seaward from the land in reclamation area. We choose 8000 to filter by counts per OTU. The mean number of OTUs in the same distance landward from the sea differed significantly between non-reclamation and reclamation areas $(p=0.018<0.05$ using t- test analysis) (Fig. 2). Therefore, reclamation activity had a significant impact the number of OTUs on coastal wetlands.

To assess whether sampling sequences provided sufficient depth of coverage to accurately describe the rhizosphere bacterial composition, random sample rarefaction curves were generated for each group. The Shannon curves represented microbial diversity index. The higher microbial diversity index got, the richer microbial richness owned. It showed that microbial diversity index in non-reclamation area was higher than that in reclamation area (Fig. 3a). The observed_species curves and Chao 1 curves can not only represented the richness of species community, but estimate as an indicator for the depth of coverage. The microbial species in non-reclamation area were higher than those in reclamation area (Fig. 3b and c). The values of phylogenetic diversity whole tree (PD_whole_tree) represented species genetic distance curve in the community. It was based on a phylogenetic tree and added all the branch lengths as a measure of diversity (Fig. 3d). These flat curves implied that the depth of sampling sequence was sufficient for the whole species from samples of reclamation and non-reclamation areas.

\section{Composition of Bacterial Communities in Rhizosphere Soil}

The relative distribution of the groups of rhizosphere bacteria varied along the sea to the land, as showed in the heatmap of

Table 1 The main physical and chemical properties of rhizosphere soil in reclamation area and non-reclamation area

\begin{tabular}{|c|c|c|c|c|c|c|c|c|c|}
\hline Sites & $\begin{array}{l}\mathrm{TN} \\
\text { Mean }(\%) \pm \mathrm{SE}\end{array}$ & $\begin{array}{l}\mathrm{TP} \\
\text { Mean }(\%) \pm \mathrm{SE}\end{array}$ & $\begin{array}{l}\mathrm{OM} \\
\text { Mean }(\%) \pm \mathrm{SE}\end{array}$ & $\begin{array}{l}\text { Salinity } \\
\text { Mean }(g / L) \pm S E\end{array}$ & Sites & $\begin{array}{l}\mathrm{TN} \\
\text { Mean }(\%) \pm \mathrm{SE}\end{array}$ & $\begin{array}{l}\mathrm{TP} \\
\text { Mean }(\%) \pm \mathrm{SE}\end{array}$ & $\begin{array}{l}\mathrm{OM} \\
\text { Mean }(\%) \pm \mathrm{SE}\end{array}$ & $\begin{array}{l}\text { Salinity } \\
\text { Mean }(g / L) \pm S E\end{array}$ \\
\hline R1 & $0.425 \pm 0.009$ & $0.052 \pm 0.014$ & $2.23 \pm 0.026$ & $2.45 \pm 0.012$ & NR1 & $0.430 \pm 0.011$ & $0.035 \pm 0.002$ & $2.46 \pm 0.036$ & $2.55 \pm 0.016$ \\
\hline $\mathrm{R} 2$ & $0.435 \pm 0.019$ & $0.049 \pm 0.009$ & $2.33 \pm 0.017$ & $2.39 \pm 0.025$ & NR2 & $0.436 \pm 0.018$ & $0.040 \pm 0.007$ & $2.92 \pm 0.021$ & $2.42 \pm 0.027$ \\
\hline R3 & $0.665 \pm 0.020$ & $0.053 \pm 0.010$ & $3.57 \pm 0.021$ & $1.86 \pm 0.027$ & NR3 & $0.457 \pm 0.022$ & $0.042 \pm 0.019$ & $3.40 \pm 0.027$ & $2.36 \pm 0.031$ \\
\hline R4 & $0.628 \pm 0.026$ & $0.057 \pm 0.005$ & $3.82 \pm 0.008$ & $1.72 \pm 0.056$ & NR4 & $0.477 \pm 0.002$ & $0.039 \pm 0.016$ & $3.99 \pm 0.015$ & $2.26 \pm 0.028$ \\
\hline R5 & $0.710 \pm 0.011$ & $0.061 \pm 0.009$ & $4.86 \pm 0.036$ & $1.50 \pm 0.067$ & NR5 & $0.535 \pm 0.008$ & $0.043 \pm 0.005$ & $4.36 \pm 0.032$ & $2.10 \pm 0.020$ \\
\hline R6 & $0.740 \pm 0.017$ & $0.064 \pm 0.008$ & $5.09 \pm 0.047$ & $1.37 \pm 0.021$ & NR6 & $0.567 \pm 0.029$ & $0.055 \pm 0.006$ & $4.57 \pm 0.014$ & $2.04 \pm 0.016$ \\
\hline R7 & $0.715 \pm 0.009$ & $0.066 \pm 0.011$ & $5.08 \pm 0.073$ & $1.52 \pm 0.025$ & NR7 & $0.615 \pm 0.018$ & $0.038 \pm 0.002$ & $4.72 \pm 0.007$ & $2.00 \pm 0.008$ \\
\hline R8 & $0.705 \pm 0.009$ & $0.073 \pm 0.012$ & $4.93 \pm 0.052$ & $1.65 \pm 0.039$ & NR8 & $0.695 \pm 0.027$ & $0.041 \pm 0.004$ & $4.91 \pm 0.016$ & $1.91 \pm 0.015$ \\
\hline R9 & $0.625 \pm 0.031$ & $0.069 \pm 0.010$ & $3.28 \pm 0.044$ & $1.98 \pm 0.008$ & NR9 & $0.715 \pm 0.025$ & $0.044 \pm 0.008$ & $5.43 \pm 0.026$ & $1.87 \pm 0.013$ \\
\hline $\mathrm{R} 10$ & $0.525 \pm 0.014$ & $0.067 \pm 0.008$ & $2.92 \pm 0.038$ & $2.07 \pm 0.017$ & NR10 & $0.728 \pm 0.006$ & $0.042 \pm 0.014$ & $5.77 \pm 0.054$ & $1.72 \pm 0.016$ \\
\hline $\mathrm{R} 11$ & $0.495 \pm 0.028$ & $0.060 \pm 0.004$ & $2.80 \pm 0.032$ & $2.22 \pm 0.033$ & NR11 & $0.756 \pm 0.012$ & $0.044 \pm 0.017$ & $5.91 \pm 0.037$ & $1.67 \pm 0.021$ \\
\hline $\mathrm{R} 12$ & $0.442 \pm 0.007$ & $0.056 \pm 0.002$ & $2.57 \pm 0.026$ & $2.30 \pm 0.031$ & NR12 & $0.774 \pm 0.004$ & $0.046 \pm 0.006$ & $6.30 \pm 0.036$ & $1.55 \pm 0.007$ \\
\hline
\end{tabular}



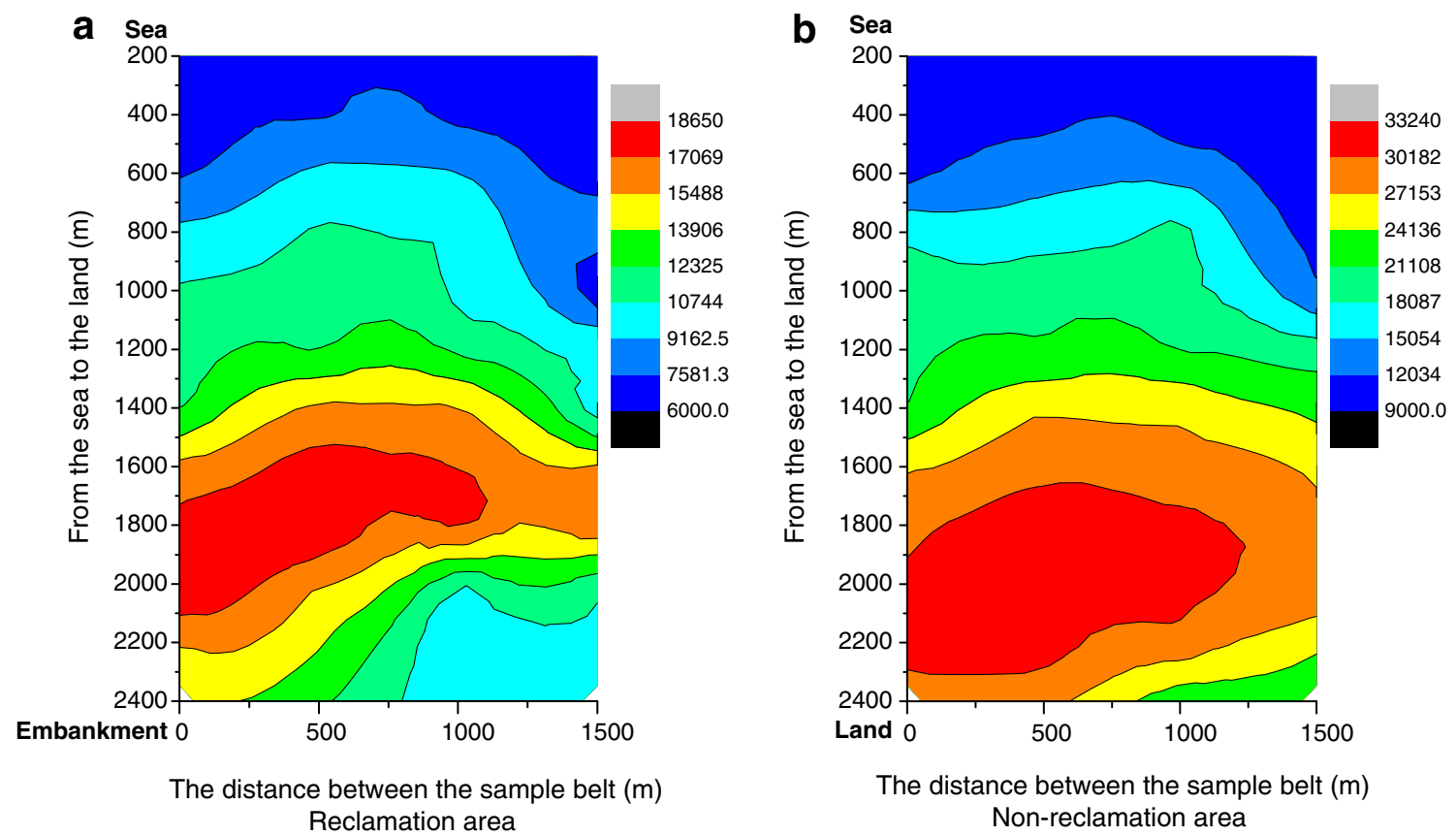

Fig. 2 Gradient distribution of the number of operational taxonomic units (OTUs) X-axis shows the distance between the sample belts with an interval of $500 \mathrm{~m}$. Y-axis shows every two sample distance from the sea to the land with an interval of $200 \mathrm{~m}$

Fig. 4, where the relative distribution of phyla assignments is clustered and plotted with respect to the different values of salinity of rhizosphere soil sites. The cluster structure shows two main groups of phyla which share a peculiar composition and abundance among the two area sites. Site R2 presented a very peculiar abundance of two phyla (Spirochaetes and Tenericutes), which resulted unrelated to salinity. As a big group of phyla appeared grouped together and uniformly distributed across the other sites, and resulted strongly correlated to salinity. In addition, Proteobacteria was found in every site.

Overall, 75 phyla were detected in the research samples. Among them, the Proteobacteria, Chloroflexi and Bacteroidetes were detected as the dominant phyla, but composition and their ratio varied in reclamation and non-reclamation areas (Fig. 5). Sixty-nine phyla in reclamation area were less than 75 phyla in non-reclamation area. The Proteobacteria, with a maximum of 111 genera, found in the samples taken landward from the sea was abundant compared with the other phyla in reclamation area. Then, the Proteobacteria had relatively homogeneous reads in the non-reclamation area. The Chloroflexi, with a maximum of 25 genera, concentrated in the middle of reclamation area, and it was relatively evenly distributed with an average 20 genera in the non-reclamation area. The Bacteroidetes, with a maximum of 14 genera, increased seaward from the land in reclamation area, and it varied the same with that containing an average 10 genera in nonreclamation area (Figs. 4 and 5).

In non-reclamation area, the Proteobacteria had no significant difference in the sampling sites $(P>0.05$ using
Duncan's multiple range test analysis), and the Chloroflexi among R7, R8 and R9 was significantly higher than that in other sampling sites $(p=0.026<0.05)$. Moreover, the Bacteroidetes in R1 and R2 were significantly higher than that in other sampling sites $(p=0.037<0.05)$, and the Bacteroidetes between R3 to R12 had no significant change. In reclamation area, the Proteobacteria significantly decreased in the seaward direction and was significantly different among the areas of R8 to R12, R3 to R7, R1 and R2 $(P<0.05$ using Duncan's multiple range test analysis). The Chloroflexi was significantly different among the area of $\mathrm{R} 8$ to R12, R3 to R7, R1 and R2 ( $P<0.05$ using Duncan's multiple range test analysis). In addition, the Bacteroidetes among R1, R2 and R3 were significantly different than those in other sampling sites at $p<0.05$ using t-test analysis (Fig. 5).

The observed differences between reclamation and nonreclamation area were represented in Fig. 6. Only a few genera were shared between the bacterial community during R10-R12 and R7-R9 in reclamation area. There was a great difference in bacterial community between reclamation and non-reclamation area. The shared genera in nonreclamation area were distributed much more evenly compared with that in reclamation area. During the shared genera, a substantial decrease in Chloroflexi of reclamation area and an increase in Chloroflexi of non-reclamation area were observed (Table 2). The shared genera Anaerolinea, Caldilinea, or Longilinea all belonging to Chloroflexi, could not be detected in any samples from R10 to R12 in reclamation area. 
a

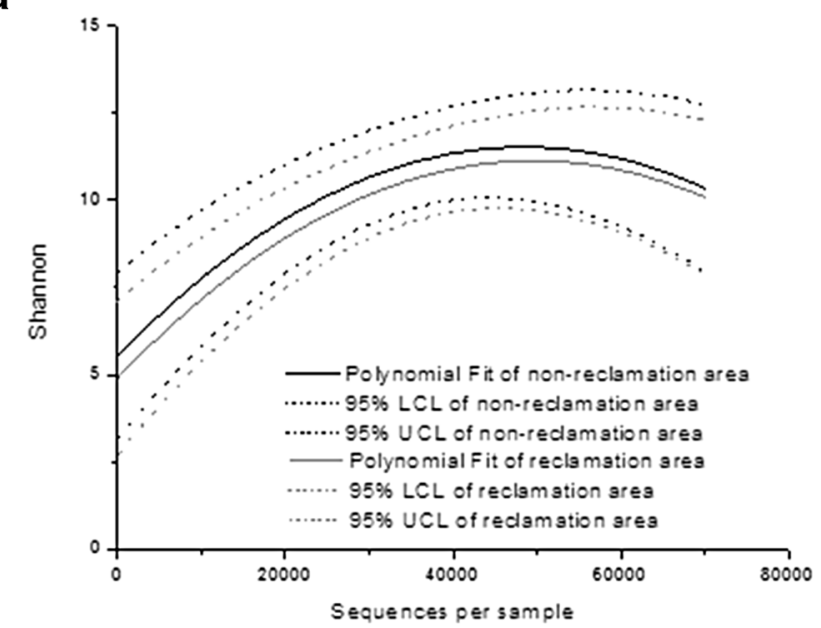

C

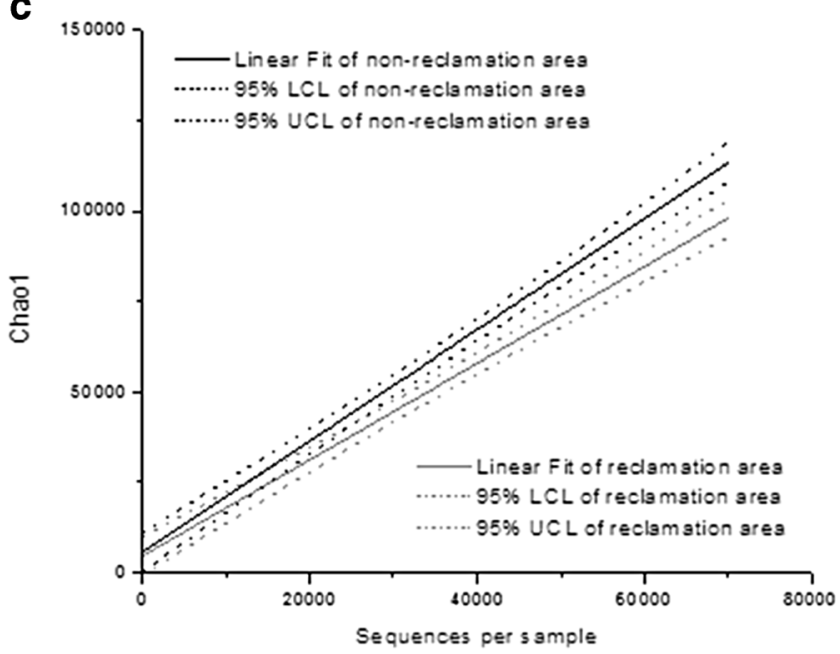

Fig. 3 Rarefaction curves of community richness estimates in reclamation and non-reclamation areas. A: $\mathrm{R}^{2}=0.5396, p<0.05 ; \mathrm{B}: \mathrm{R}^{2}=896, p<0.05$; $\mathrm{C}: \mathrm{R}^{2}=0.835, p<0.05 ; \mathrm{D}: \mathrm{R}^{2}=748, p<0.05$. The $\mathrm{x}$-axis represents sample sequences, and the $\mathrm{y}$-axis represents different index rarefaction
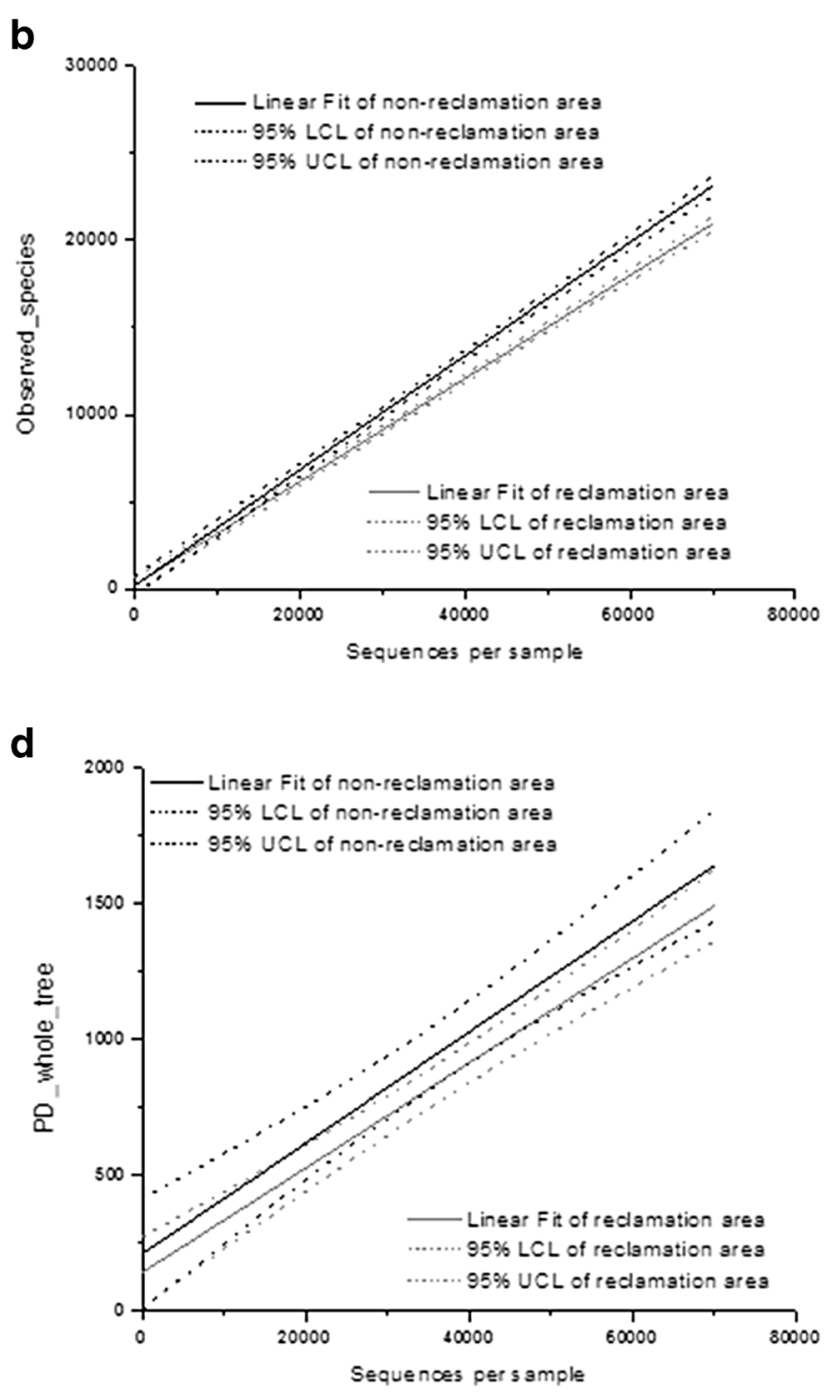

values. A solid black line represents linear fit of all curves in nonreclamation area $(n=12)$. The two dotted black lines represent confidence bands. A solid gray line represents linear fit of all curves in reclamation area $(n=12)$. The two dotted gray lines represent confidence bands

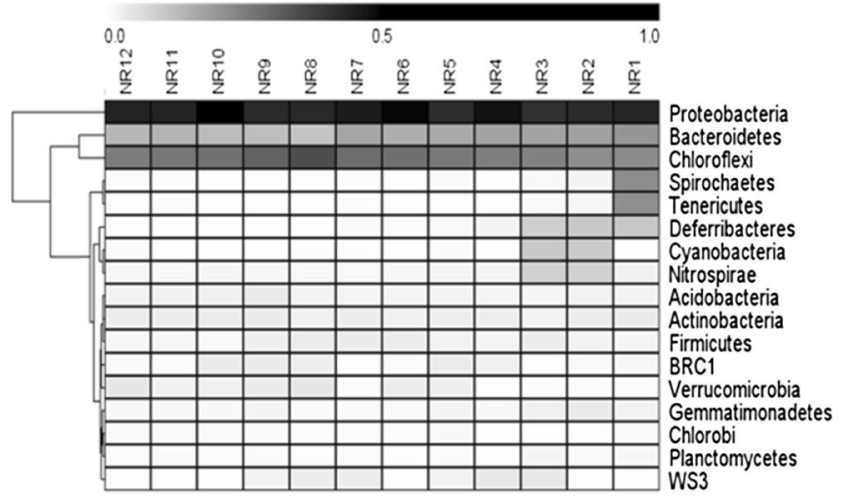

Heatmap of Phyla assignments in the non-reclamation area

Fig. 4 Heatmap of Phyla assignments. The heatmap reports the normalized values of the taxonomic assignments at phylum level. The color value from 0.0 to 1.0 represents the relative distribution. Each column (R1-R12) of the heatmap shows the phyla's relative abundance

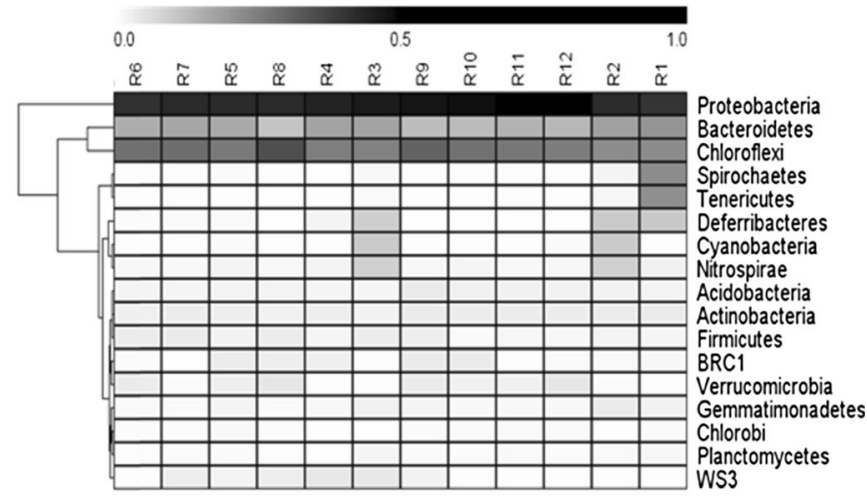

Heatmap of Phyla assignments in the reclamation area

in a sampling site. The columns of the heatmap are ordered according to the degree of salinity in the sampling sites (from the lowest values, at the left, to the higher, at the right). The distance between every two sample sites is an interval of $200 \mathrm{~m}$ 

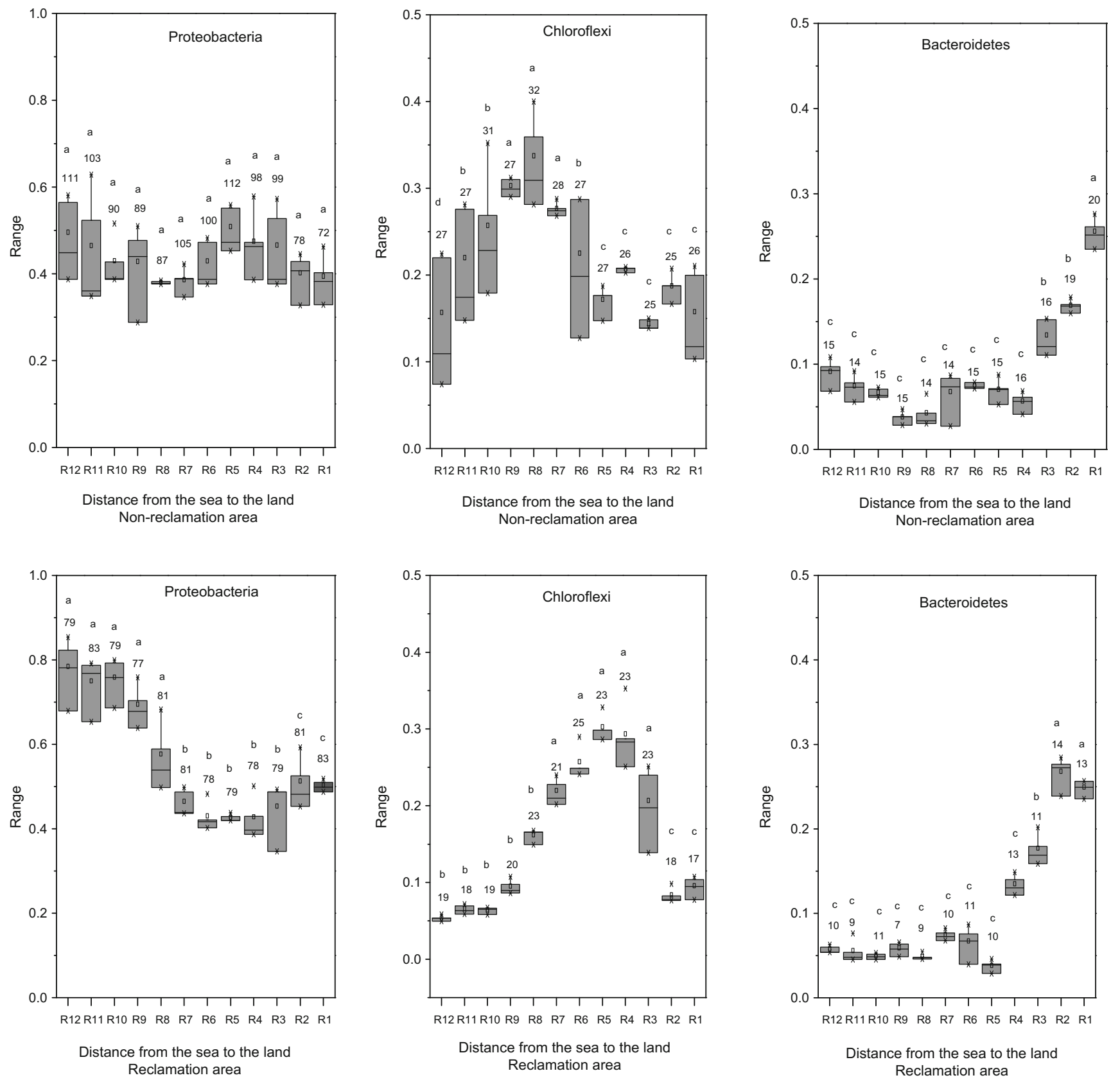

Fig. 5 The relative abundance of the three main bacterial phyla. X-axis represents a distance between every two sampling sites with an interval of $200 \mathrm{~m}$ from the sea to the land. Box plot showing the relative abundance of the three main bacterial phyla found in reclamation and nonreclamation area: Proteobacteria, Chloroflexi and Bacteroidetes

represented as range on the Y-axis. The numbers above the boxes denote the number of genera composing each phylum. Boxes with a different letter above their whiskers are significantly different at $P<0.05$ using t-test analysis

\section{Relationships Between Bacterial Relative Abundance and Physicochemical Factors}

In order to highlight the influence of these physicochemical properties on the bacterial community structure and to compare the bacterial relative abundance among reclamation and non-reclamation areas, salinity, TN, TP and OM of each rhizosphere soil site were used as variables in the CCA analysis
(Fig. 7a). The CCA analysis based on permutations gave a clear show of the variability expressed by the different sites. It shows that different ecological niches for physical and chemical properties with respect to bacterial communities. Figure 7a showed that the first and the second axis explained $67.69 \%$ of the total variability. The second axis was highly significant negative correlation with salinity, and significantly positive correlation with $\mathrm{TN}$ and $\mathrm{TP}$. The result indicated that 


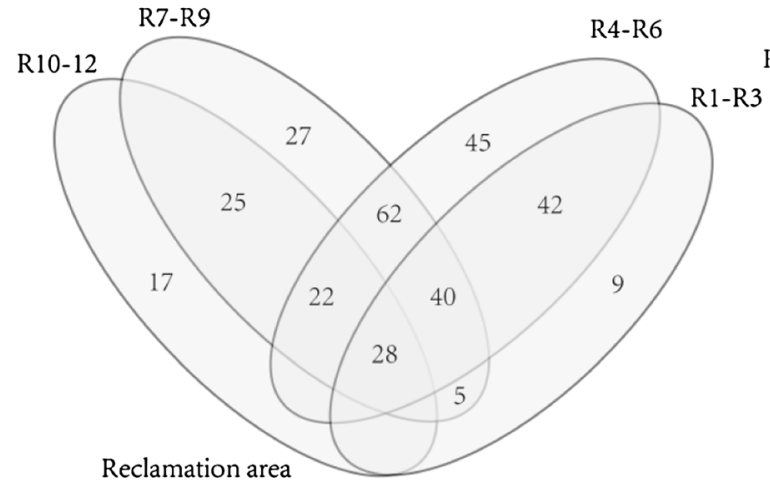

Fig. 6 Venndiagrams show the shared genera in reclamation and nonreclamation areas. Levels of R1-R12 were set the direction from the sea to the land along a transect perpendicular to the coastline. Level R1-R3

the salinity affects the distribution of the bacterial relative abundance in rhizosphere soil. Anaerolinea has significantly positive correlation with salinity. It indicated that Anaerolinea can provide an indicator to response the environment change. It may mean that more salt water-born bacteria would be found in non-reclamation area comparing to that in reclamation area.

Principal component analysis is shown in Fig. 7b. The abundances of bacterial phyla in each sample were used

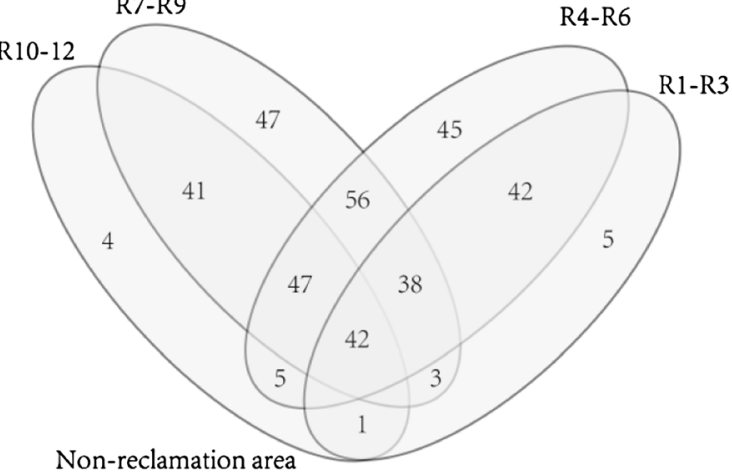

represents the nearest distance to the sea, and Level R10-12 represents the farthest distance to the sea. The level R10-12 of reclamation area represents the nearest distance to the embankment

as variables, together with rhizosphere soil physicochemical properties, while the rhizosphere soil sites were used as observations. Using the first and the second axis together, it's explained about $60.95 \%$ of the total variability of data. The variability of rhizosphere soil properties between the sites of non-reclamation and reclamation area corresponded to a diverse relative abundance of bacterial phyla. The results actually showed a different degree of correlation with soil physicochemical character.

Table 2 Shared genera between different sampling sites

\begin{tabular}{|c|c|c|c|c|c|c|c|c|c|}
\hline \multirow[t]{2}{*}{ Phylum } & \multirow[t]{2}{*}{ Genus } & \multicolumn{4}{|c|}{ Reclamation area } & \multicolumn{4}{|c|}{ Non-reclamation area } \\
\hline & & $\begin{array}{l}\text { R10-R12 } \\
(\%)\end{array}$ & $\begin{array}{l}\text { R7-R9 } \\
(\%)\end{array}$ & $\begin{array}{l}\text { R4-R6 } \\
(\%)\end{array}$ & $\begin{array}{l}\text { R1-R3 } \\
(\%)\end{array}$ & $\begin{array}{l}\text { NR10-NR12 } \\
(\%)\end{array}$ & $\begin{array}{l}\text { NR7-NR9 } \\
(\%)\end{array}$ & $\begin{array}{l}\text { NR4-NR6 } \\
(\%)\end{array}$ & $\begin{array}{l}\text { NR1-NR3 } \\
(\%)\end{array}$ \\
\hline \multirow[t]{10}{*}{ Proteobacteria } & Psychromonas & 21.21 & 21.06 & 21.13 & 31.33 & 32.11 & 25.54 & 29.13 & 30.17 \\
\hline & Arcobacter & 22.83 & 22.42 & 28.94 & 27.62 & 22.14 & 32.12 & 27.17 & 22.53 \\
\hline & Sulfurimonas & 2.48 & 2.61 & 1.93 & 1.37 & 2.48 & 2.62 & 0.23 & 1.52 \\
\hline & Serratia & 2.83 & 3.22 & 2.72 & 1.38 & 0.53 & 1.46 & 3.22 & 0.61 \\
\hline & Ferrimonas & 1.32 & 2.15 & 1.32 & 0.84 & 1.44 & 3.05 & 0.62 & 0.56 \\
\hline & Shewanella & 0.43 & 0.33 & 0.21 & 0.23 & 0.83 & 0.22 & 0.43 & 0.82 \\
\hline & Desulfococcus & 1.23 & 1.57 & 0.89 & 2.00 & 1.62 & 1.48 & 0.67 & 1.07 \\
\hline & Octadecabacter & 3.17 & 2.16 & 0.45 & 0.61 & 1.27 & 3.02 & 0.14 & 0.21 \\
\hline & Novosphingobium & 3.87 & 3.54 & 2.62 & 1.54 & 1.37 & 2.04 & 2.21 & 1.38 \\
\hline & Geobacter & 2.11 & 3.87 & 2.13 & 0.54 & 2.05 & 0.25 & 0.53 & 0.24 \\
\hline \multirow[t]{5}{*}{ Chloroflexi } & Anaerolinea & & 16.31 & 13.54 & 12.10 & 10.35 & 10.35 & 11.64 & 13.35 \\
\hline & Caldilinea & & & 3.54 & 3.32 & 3.95 & 3.26 & 3.96 & 3.47 \\
\hline & Dehalogenimonas & & & 3.17 & 3.09 & 3.35 & 3.93 & 3.34 & 3.42 \\
\hline & Thermogemmatisp & & & 2.54 & 2.12 & 1.44 & 1.57 & 1.96 & 2.05 \\
\hline & Longilinea & & & & 1.34 & 1.06 & 1.42 & 1.33 & 1.86 \\
\hline \multirow[t]{6}{*}{ Bacteroidetes } & Prevotella & 5.76 & 5.09 & 4.43 & 0.97 & 1.35 & 0.43 & 1.64 & 1.19 \\
\hline & Gramella & 0.89 & 0.22 & 1.17 & 1.45 & 1.04 & 0.67 & 2.41 & 2.07 \\
\hline & Flavobacterium & 1.64 & 1.06 & 1.81 & 1.62 & 1.43 & 0.54 & 1.38 & 2.06 \\
\hline & Salegentibacter & 4.08 & 3.08 & 1.90 & 1.35 & 1.68 & 1.00 & 1.92 & 0.51 \\
\hline & Tenacibaculum & 2.34 & 1.52 & 1.20 & 0.95 & 1.92 & 0.45 & 2.10 & 1.66 \\
\hline & sum & 76.19 & 90.21 & 95.64 & 95.77 & 93.41 & 96.42 & 96.03 & 90.75 \\
\hline
\end{tabular}




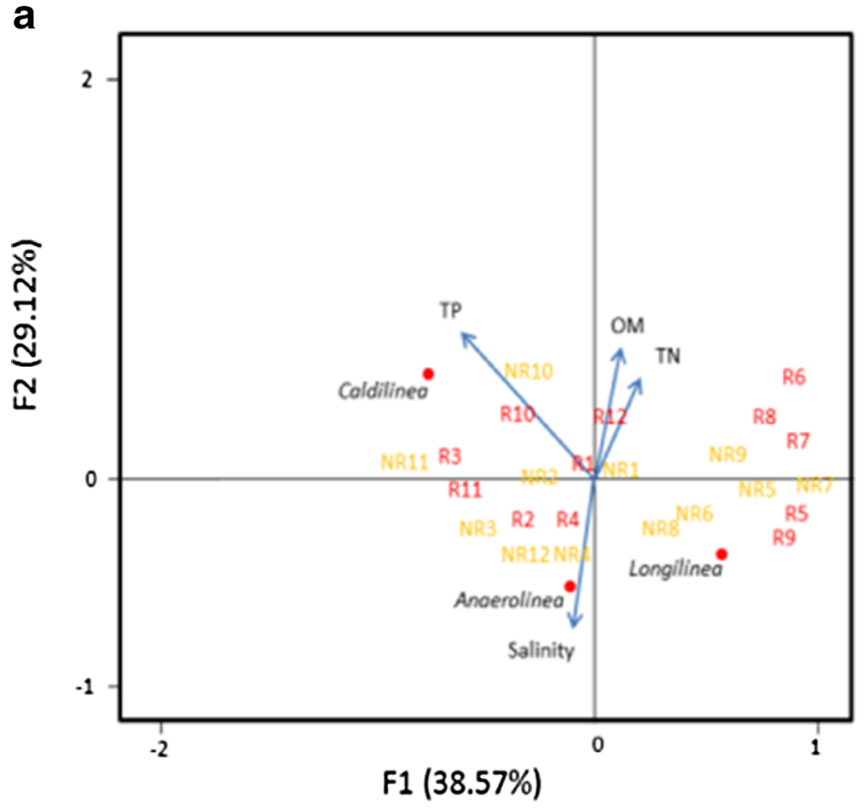

Fig. 7 Canonical correlation analysis (CCA) and principal component analysis (PCA). Canonical correlation analysis (CCA) is on the basic on bacterial community data. Physical and chemical properties of each site have been run on the CCA analysis in order to inspect the relevance to the bacterial relative abundance. Principal component analysis (PCA) of bacterial communities as affected by rhizosphere soil properties, based

Obviously, there is an inverse relationship between bacterial phyla. It indicated that the presence of some composition of bacteria in a site could be the reason for the absence of others.

Spearman rank correlations analysis of the mean values of physical-chemical properties and bacterial relative abundance in R1-R12 of reclamation area are shown in Table 3. Reclamation activity affected the distribution of the nutrient contents and bacterial relative abundance. The analysis determined that salinity and bacterial relative abundance in R1-R3, R4-R6 and R7-R9 had highly significant negatively correlation $(p<0.01)$, in $\mathrm{R} 10-\mathrm{R} 12$ had significant negatively correlation $(p<0.05)$. All the reclamation area, OM and bacterial relative abundance had highly significant positively correlation $(p<0.01)$, meanwhile, TN and OM had significant positively correlation $(p<0.05)$. OM and salinity were highly significantly negatively correlated in R1-R3, R4-R6 and R7-R9 $(p<0.01)$, significantly negatively correlated in R10-R12 $(p<0.05)$. Respectively, TN and bacterial relative abundance, $\mathrm{TN}$ and $\mathrm{OM}$ were significantly positively correlated in R1-R3, $\mathrm{R} 4-\mathrm{R} 6$ and $\mathrm{R} 7-\mathrm{R} 9(p<0.05)$, whereas $\mathrm{TN}$ and bacterial relative abundance, TN and $\mathrm{OM}$ had no significant correlation in R10-R12. TP and physical-chemical properties in soils had no significant correlation.

The regression analysis on all areas (R1-R12) from the sea to the land determined the coefficient $\mathrm{R}^{2}$ as $0.317(p<0.05)$. This result was attributed to increase temporal salinity by reclamation embankment that blocked water exchange.

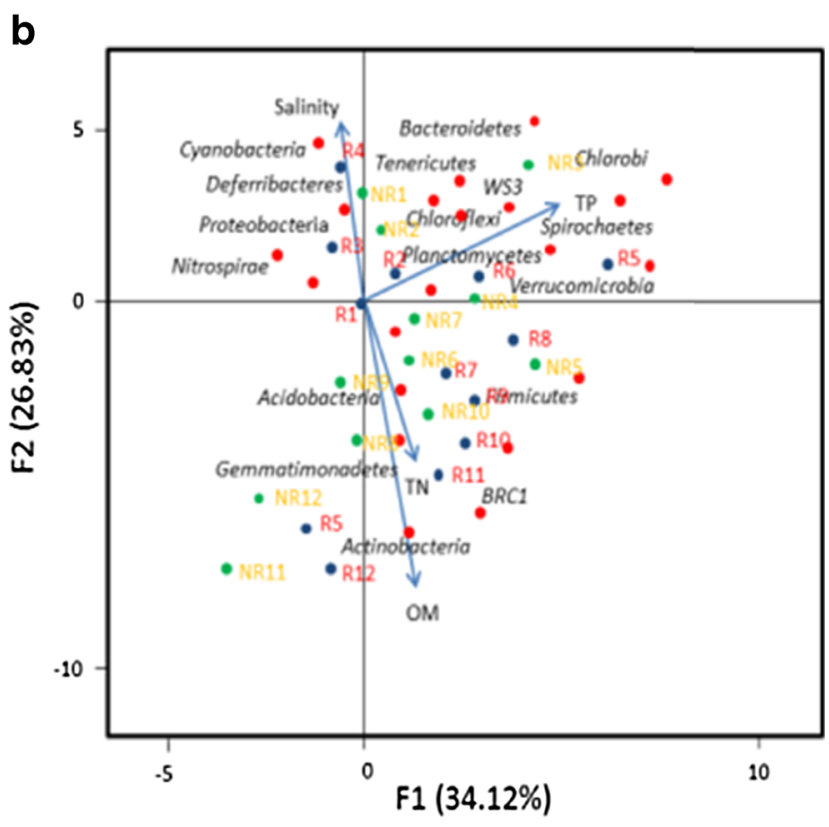

on the abundance of bacterial genera (A) and phyla (B). Every vector points to the direction, and the increase direction for a given variable. Rhizosphere soil sites with similar bacterial communities are localized in similar positions. R1-R12 and NR1-NR12 represent sampling sites; arrows represent physical and chemical properties

Therefore, regression analysis was conducted after R9-R12 area were removed; the coefficient $\mathrm{R}^{2}$ was $0.346(p<0.05)$. This value showed that rhizosphere soil bacterial diversity significantly increased with the reduction in salinity.

\section{Discussion}

\section{The Difference on Rhizosphere Soil Properties}

The results of this study determined that the bacteria showed a sign of accumulation in a land-to-sea direction. The degree of aggregation may occur because of the reclamation embankment. This result was probably caused by the extrusion of embankment which thereby impacted the soil that resulted in the change of the physicochemical structure of the soil.

Results showed that soil bacterial relative abundance was declined gradually from the land to the sea.TN, TP, and OM in soils showed an increasing trend from the sea to land, which was consistent with the research on physicochemical property in the Yangtze Estuary (Cui et al. 2012). In our study, organic matter and bacterial relative abundance all the time had highly significant positively correlation in reclamation area. The relationship between organic matter and bacterial relative abundance had no influenced by reclamation embankment. Salinity can directly affect the environmental impacts of reclamation. Reclamation embankment accelerated the reduction of soil salinity as the elevation increased from sea to land (R1-R9), 


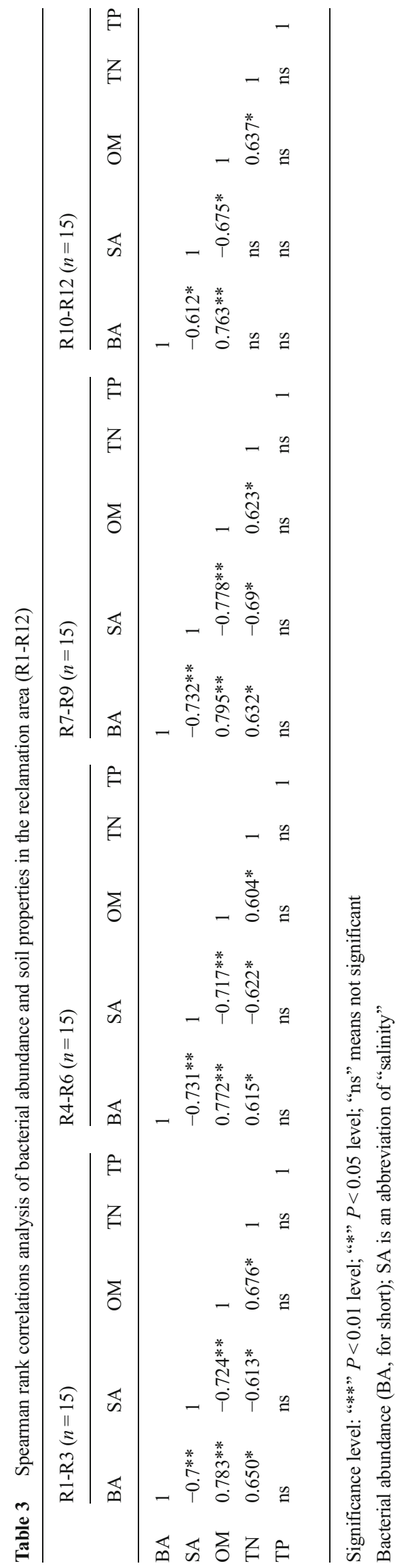

but salinity gradually increased in close to the embankment (R10-R12). Embankment broke plant growth and led to plant death, which cause salinity storage in the soil. Meanwhile, little plant can grow on the high salt level, which caused the decrease of organic matter. Bacterial relative abundance was reduced in the R1-R12 of reclamation area because organic matter was the main source of energy for microorganisms. Sudipta et al. (2006) reported that soil organic carbon was negatively correlated with soil salinity. Reclamation embankment activity may affect the soil salinity.

\section{Potential Influence of Salinity on Main Microorganism Group}

Ma and Gong (2013) reported that $90 \%$ of the bacterial sequences they enumerated belonged to Proteobacteria, Bacteroidetes and Chloroflexi, which were also detected in our study. Previous studies indicate that many Proteobacteria are found in soil, and these microorganisms are numerous in plant rhizosphere region (Dedysh et al. 2006; Wobus et al. 2003). Proteobacteria has the largest proportion in bacterial community composition from quantity and variety (Ai et al. 2015), which has been proven in the present study. Chloroflexi was found in hypersaline wastewater (ValenzuelaEncinas et al. 2009), and is known to be a potential phototroph. Chloroflexi has a wide variability of space distribution in various plants species and also affects temperature, moisture ( $\mathrm{Li}$ et al. 2014). In present research, salinity has affected the distribution rule of Chloroflexi in wetland ecosystem to some extent and decreased the proportion of Chloroflexi. Previous studies reported that high salinity directly suppressed the heterotrophic metabolic capabilities (Xi et al. 2014). Furthermore, high salinity might enhance water osmotic pressure, which caused microbial community changes. In the present study, a few various species of heterotrophic bacteria, such as $\beta$-Proteobacteria was noted in R10-R12 of non-reclamation area. The results showed that a substantial decrease were associated with salinity variation. Distribution of Bacteroidetes was relatively rare in this research compared with other phyla. Salinity reduced the abundance values of rhizosphere bacteria and the relative content of Chloroflexi in soil. Salinity caused the changes of physicochemical feature and bacterial relative abundance. Previously published studies determined that changes in soil salinity have an impact on the microbial community in mangrove areas (Zhang et al. 2008). The differences in bacterial composition and diversity are due to a variable salt concentration in nature saline soil (Canfora et al. 2014). However, in some cases, there is an inverse relationship among bacterial phyla. In this study, opposite behavior is found in phyla composition which is strongly related. The situation seems to occur in the same sites when the same environmental conditions occur. As the microenvironment changed, the bacterial relative abundance is adjusted. There 
is something magical and composition change about being in the present of environment disturbance. It emerged that the bacterial community composition is not unique, but many bacterial community composition. The need us to investigate more place and do long-term experiment. Of course, microbial diversity also might be higher over time or finally become greater than that in the undisturbed site, which indicated importance of long-term monitoring and investigation in the future.

In conclusion, the analysis results showed salt concentration can effect on differences in bacterial relative abundance and composition diversity due to a variable in the rhizosphere soil. Bacterial relative abundance in reclamation area was significantly lower than that in non-reclamation area. The bacterial community composition showed a statistically significant to spatial variability. Some bacterial phyla exit in the whole study area, out of accordance with salinity control. It means that the composition of bacterial community was varied for the environment disturbance, but it was not unique correlated to environment factor. Anaerolinea genus has significantly positive correlation with salinity. It indicated that Anaerolinea genus can provide an indicator to response the environment change.

Acknowledgments This research was provided by the National Key Basic Research Program of China (2013CB430406), China National Funds for Distinguished Young Scientists (51125035), and National Science Foundation for Innovative Research Group (51121003).

Open Access This article is distributed under the terms of the Creative Commons Attribution 4.0 International License (http:// creativecommons.org/licenses/by/4.0/), which permits unrestricted use, distribution, and reproduction in any medium, provided you give appropriate credit to the original author(s) and the source, provide a link to the Creative Commons license, and indicate if changes were made.

\section{References}

Ai C, Liang GQ, Sun JW, Wang XB, He P, Zhou W, He XH (2015) Reduced dependence of rhizosphere microbiome on plant-derived carbon in 32-year long-term inorganic and organic fertilized soils. Soil Biology and Biochemistry 80:70-78

Canfora L, Bacci G, Pinzari F, Lo papa G, Dazzi C, Benedetti A (2014) Salinity and bacterial diversity: to what extent does the concentration of salt affect the bacterial community in a saline soil? PLoS One. doi:10.1371/journal.pone.0106662

Caporaso JG, Lauber CL, Costello EK, Berg-Lyons D, Gonzalez A, et al. (2011) Moving pictures of the human microbiome. Genome Biol 12: R50. doi:10.1186/gb-2011-12-5-r50

Chen X, Su Y, He X, Wei Y, Wei W, Wu J (2012) Soil bacterial community composition and diversity respond to cultivation in Karst ecosystems. World Journal of Microbiology and Biotechnology 28(1):205-213

Cui J, Liu C, Li ZL, Wang L, Chen XF, Ye ZZ, Fang CM (2012) Longterm changes intop soil chemical properties under centuries of cultivation after reclamation of coastal wetlands in the Yangtze Estuary, China. Soil Tillage Research 123:50-60
Cui BS, Yang QC, Yang ZF, Zhang KJ (2009) Evaluating the ecological performance of wetland restoration in the Yellow River Delta, China. Ecological Engineering 35:1090-1103

Dobbelaere S, Vanderleyden J, Okon Y (2003) Plant growth-promoting effects of diazotrophs in the rhizosphere. Critical Reviews in Plant Sciences 22:107-149

Douterelo I, Goulder R, Lillie M (2010) Soil microbial community response to land management and depth, related to the degradation of organic matter in English wetlands: implications for the in situ preservation of archaeological remains. Applied Soil Ecology 44:219-227

Dedysh SN, Pankratov TA, Belova SE, Kulichevskaya IS, Liesack W (2006) Phylogenetic analysis and in situ identification of Bacteria community composition in an acidic Sphagnum peat bog. Applied and Environmental Microbiology 72:2110-2117

De Groot RS, Wilson MA, Boumans RMJ (2002) A typology for the classification description and valuation of ecosystem functions goods and services. Ecological Economics 41:393-408

Dunbar J, Eichorst SA, Gallegos-Graves LV, Silva S, Xie G, Hengartner NW, Evans RD, Hungate BA, Jackson RB, Megonigal JP, Schadt CW, Vilgalys R, Zak DR, Kuske CR (2012) Common bacterial responses in six ecosystems exposed to 10 years of elevated atmospheric carbon dioxide. Environmental Microbiology 14(5):11451158

Fellet G, Marchiol L, Delle Vedove G, Peressotti A (2011) Application of biochar on mine tailings: effects and perspectives for land reclamation. Chemosphere 83:1262-1267

Hartmana WH, Richardson CJ, Vilgalys R, Bruland GL (2008) environmental and anthropogenic controls over bacterial communities in wetland soils. PNAS 105:17842-17847

Jiang X, Jin XC, Yao Y, Li LH, Wu FC (2008) Effects of biological activity, light, temperature and oxygen on phosphorus release processes at the sediment and water interface of Taihu Lake, China. Water Research 42:2251-2259

Knelman JE, Legg TM, O'Neill SP, Washenberger CL, Gonzalez A, Cleveland CC, Nemergut DR (2012) Bacterial community structure and function change in association with colonizer plants during early primary succession in a glacier forefield. Soil Biology and Biochemistry 46:172-180

Li P, Dong JY, Yang SF, Bai L, Wang JB, Wu GG, Wu X, Yao QH, Tang $\mathrm{XM}$ (2014) Impact of $\beta$-carotene transgenic rice with four synthetic genes on rhizosphere enzyme activities and bacterial communities at different growth stages. European Journal of Soil Biology 65:40-46

Lin YT, Huang YJ, Tang SL, Whitman WB, Coleman DC, Chiu CY (2010) Bacterial community diversity in undisturbed perhumid montane forest soils in Taiwan. Microbial Ecology 59(2):369-378

López-Fuentes E, Ruíz-Valdiviezo VM, Martínez-Romero E, GutiérrezMiceli FA, Dendooven L, Rincón-Rosales R (2012) Bacterial community in the roots and rhizosphere of Hypericum silenoides Juss. 1804. African Journal of Microbiology Research 6(11):2704-2711

Magoc T, Salzberg SL (2011) FLASH: Fast length adjustment of short reads to improve genome assemblies. Bioinformatics 27(21):29572963

Ma B, Gong J (2013) A meta- analysis of the publicly available bacterial and archaeal sequence diversity in saline soils. World Journal of Microbiology and Biotechnology 29:2325-2334

Marimuthu S, Reynolds DA, Le Gal La Salle C (2005) A field study of hydraulic, geochemical and stable isotope relationships in a coastal wetlands system. Journal of Hydrology 315:93-116

Martin BC, George SJ, Price CA, Ryan MH, Tibbett M (2014) The role of root exuded low molecular weight organic anions in facilitating petroleum hydrocarbon degradation: current knowledge and future directions. Science of the Total Environment 472:642-653

Moore TLC, Hunt WF (2012) Ecosystem service provision by stormwater wetlands and ponds-A means for evaluation? Water Research 46:6811-6823 
Park SR, Kim JH, Kang CK, An S, Chung IK, Kim JH, Lee KS (2009) Current Status and ecological roles of Zostera marina after recovery from large-scale reclamation in Nakdong River estuary, Korea. Estuarine. Coastal and Shelf Science 81:38-48

Prosser JI (2002) Molecular and functional diversity in soil micro-organisms. Plant and Soil 244:9-17

Sarkar P, Yamasaki S, Basak S, Bera A, Pk B (2012) Purification and characterization of a new alkali-thermostable lipase from Staphylococcus aureus isolated from Arachis hypogaea rhizosphere. Process Biochemistry 47:858-866

Shen Y, Ehrenfeld JG (2009) The effects of changes in soil moisture on nitrogen cycling in acid wetland types of the New Jersey Pinelands (USA). Soil Biology and Biochemistry 41:2394-2405

Stottmeister U, Wießner A, Kuschk P, Kappelmeyer U, Kastner M, Bederski O, Muller RA, Moormann H (2003) Effects of plants and microorganisms in constructed wetlands for wastewater treatment. Biotechnology Advances 22:93-117

Sudipta T, Sabitri K, Ashis C, Arindam G, Kalyan C, Bimal KB (2006) Microbialbiomass and its activities in salt-affected coastal soils. Biology and Fertility of Soils 42:273-277

Toal ME, Yeomans C, Killham K, Meharg AA (2000) A review of rhizosphere carbon flow modeling. Plant and Soil 222:263-281

Valenzuela-Encinas C, Neria-Gonzalez I, Alcantara-Hernandez RJ, Estrada-Alvarado I, Zavala-Diaz de la Serna FJ et al (2009) Changes in the bacterial populations of the highly alkaline saline soil of the former lake Texcoco (Mexico) following flooding. Extremophiles 13:609-621

Venosa AD, Zhu XQ (2003) Biodegradation of crude oil contaminating marine shorelines and freshwater wetlands. Spill Science Technology Bulletin 8:163-178

Veneklaas EJ, Stevens J, Cawthray GR (2003) Chickpea and white lupin rhizo-sphere carboxylates vary with soil properties and enhance phosphorus uptake. Plant and Soil 248:187-197
Waldrop MP, Harden JW, Turetsky MR, Petersen DG, McGuire AD, Briones MJI, Churchill AC, Doctor DH, Pruett LE (2012) Bacterial and enchytraeid abundance accelerate soil carbon turnover along a lowland vegetation gradient in interior Alaska. Soil Biology and Biochemistry 50:188-198

Wang JL, Xn R, Chen CL (2000) General review in the study of barrier mechanism caused by continuous soybean cropping. Soybean Science 19(4):367-371

Wobus A, Bleul C, Maassen S, Schuppler C, Schuppler M, Jacobs E, Roske I (2003) Microbial diversity and functional characterization of sediments from reservoirs of different trophicstates. FEMS Microbiology Ecology 46:331-347

Xi XF, Wang L, Hu JJ, Tang YS, Hu Y, Fu XH, Sun Y, Tsang YF, Zhang YN, Chen JH (2014) Salinity influence on soil microbial respiration rate of wetland in the Yangtze River estuary through changing microbial community. Journal of Environment Sciences 26:2562-2570

$\mathrm{Xu}$ XG, Lin HP, Fu ZY (2004) Probe into the method of regional ecological risk assessment-a case study of wetland in the Yellow River Delta in China. Journal of Environmental Management 70(3):253262

Yu G, Zhang JY (2011) Analysis of the impact on ecosystem and environment of marine reclamation-A case study in Jiaozhou Bay. Energy Procedia 5:105-111

Zhang Y, Cui BS, Wang SR, Chu ZS, Fan XY, Hua YY, Lan Y (2012) Relation between enzyme activity of sediments and lake eutrophication in grass-type lakes in North China. Clean-Soil Air, Water 40: $1145-1153$

Zhang YB, Lin P, Wei XY, Zhuang TC (2008) Effect of salinity on microbial densities of soil in the dilution plate technique applied in mangrove areas. Acta Ecologica Sinica 28:1287-1295 